\title{
Clinical Profile and Treatment Outcome of Spinal Epidural Arachnoid Cysts: A Systematic Review of Case Studies and Reports
}

\author{
Aditya K. Patil ${ }^{1}$ Srikant K. Swain ${ }^{1}$ Suresh Sharma ${ }^{2}$ Rajnish Kumar Arora ${ }^{1}$ Achal Sharma ${ }^{3}$
}

Poonam Arora ${ }^{4}$ Radhey S. Mittal ${ }^{1}$

${ }^{1}$ Department of Neurosurgery, All India Institute of Medical Sciences, Dehradun, Uttarakhand, India

${ }^{2}$ College of Nursing, All India Institute of Medical Sciences, Dehradun,

Address for correspondence Rajnish Kumar Arora, MCh, Department of Neurosurgery, All India Institute of Medical Sciences, Rishikesh, Dehradun, Uttarakhand, India Uttarakhand, India

(e-mail: rajnish.nsurg@aiimsrishikesh.edu.in).

${ }^{3}$ Department of Neurosurgery, SMS Medical College, Jaipur,

Rajasthan, India

${ }^{4}$ Department of Emergency Medicine, All India Institute of Medical

Sciences, Dehradun, Uttarakhand, India

Indian J Neurosurg 2023;12:3-9.

\begin{abstract}
Keywords

- spinal epidural arachnoid cyst

- spinal extradural

- dural defect repair

Background A spinal epidural arachnoid cyst (SEAC) is a rare clinical entity. We performed a systematic review of the literature to obtain information regarding demographics, clinical presentation, treatment modalities, and outcome of SEACs.

Methods A literature search was performed by using the databases PubMed/Medline, PubMed Central, Embase, Cochrane Library, Ovid MEDLINE, and Ovid Medline InProcess. A total of 170 articles were found on literature search. We found 575 cases of SEAC since 1904 for inclusion in the review including three cases which were operated by us. We studied the patient characteristics, clinical features, and management strategies, and evaluated their outcome.

Results The average age of presentation was 30 years with a male:female ratio of $1.03: 1$. They are commonly seen in the thoracic region (42.3\%). The length of cyst was more than two vertebral levels in $85.81 \%$. Mean symptom duration was 29 months, with most common presentation being that of compressive myelopathy. A good clinical outcome was present in symptomatic patients who had a shorter symptom duration and underwent complete surgical excision of the SEAC. Age, sex, length of lesion, and presence of dural defect did not have a bearing on the surgical outcome.

Conclusion For thoracic compressive myelopathy in a young patient, SEAC should be kept as a differential diagnosis. Surgical complete excision of the cyst with meticulous closure of the dural defect is the standard in management for a good clinical outcome.
\end{abstract}

DOI https://doi.org/ 10.1055/s-0041-1731623. ISSN 2277-954X. (c) 2021. Neurological Surgeons' Society of India. All rights reserved. This is an open access article published by Thieme under the terms of the Creative Commons Attribution-NonDerivative-NonCommercial-License, permitting copying and reproduction so long as the original work is given appropriate credit. Contents may not be used for commercial purposes, or adapted, remixed, transformed or built upon. (https://creativecommons.org/ licenses/by-nc-nd/4.0/)

Thieme Medical and Scientific Publishers Pvt. Ltd., A-12, 2nd Floor, Sector 2, Noida-201301 UP, India 


\section{Introduction}

Spinal epidural arachnoid cysts (SEACs) are a rare entity, accounting for less than $1 \%$ of all spinal epidural lesions. ${ }^{1}$ They are known by various names such as arachnoid cysts, arachnoid pouches, arachnoid diverticula, meningeal cysts, and dural cysts. Most of the literatures pertaining to SEAC are case reports except for a few.

Various theories regarding pathogenesis and expansion of the cyst are described in the literature. It is believed that they are produced by a small defect in the dural layer leading to arachnoid layer pouching out of it and gradually increasing in size sufficient to produce compressive features. ${ }^{2}$ However, the exact etiology, whether congenital or acquired, is still unclear, as in some case reports the authors could not find the dural defect. ${ }^{3}$ A genetic etiology has been described in some cases pointing toward familial origin.

A patient may present with symptoms of pain, weakness, and bladder and bowel incontinence. Magnetic resonance imaging (MRI) is the advocated imaging modality, but computed tomography (CT) myelography or water soluble contrast myelography is also used to identify the dural defect. ${ }^{4}$ Recent advances in imaging techniques have enabled us to visualize the dural defect accurately. Diverse modalities of management from conservative management of asymptomatic cysts to cyst aspiration, fenestration, surgical excision, partial resection, and cystoperitoneal shunting have been advocated. $^{5}$ Minimal invasive approaches have also been utilized in some cases. Various treatment modalities have thus been described for this entity; however, the exact outcome of these modalities has not yet been systematically reviewed. Hence, we performed a systematic review of the literature to assess an appropriate management strategy and outcomes in these lesions. Our aim was to analyze the demographic data, patient characteristics, symptomatology, and outcome of surgery in these cases.

\section{Methods}

The literature search was performed in compliance to PRISMA (Preferred Reporting Items for Systematic Reviews and Meta-Analyses) guidelines. A comprehensive search of several databases for case reports and series from 1904 to May 2020 was performed. The databases included PubMed/Medline, PubMed Central, Embase, Cochrane Library, and Ovid MEDLINE. Also gray area search was performed using "Google Scholar" search engine. The search was done using MeSH terms and also by using free text keywords. The MeSH terms used for PubMed and Embase were Arachnoid cyst, Spinal canal, central nervous system cysts, epidural space, and spinal cord compression. The full list of keywords used for search in Ovid includes Spinal extradural arachnoid cyst, spinal extradural leptomeningeal cyst, spinal arachnoid diverticula, SEAC, spinal dural defect, SEAC, and spinal epidural leptomeningeal cyst. The same keywords were also used for free-text searching. Search was limited to articles written in English language only and the articles written in language other than English were excluded.

The titles and abstracts of the articles retrieved from the search were screened for relevance. Articles not relevant to the study were excluded. The full-text publications were then reviewed, and only case reports and series concerning SEACs were included in this systematic review. Exclusion criteria for the full-text screen included "no" relevance to SEAC, articles in language other than English, conference abstracts, redundant articles, withdrawn articles, and book chapters. A summary of the literature screening and selection is presented in - Supplementary Fig. S1 (PRISMA flow diagram). Once the final list of articles meeting the inclusion criteria was compiled, the following points of data were abstracted from each study: patient age and sex; cyst characteristics (level, size, extensions), clinical presentation, preoperative imaging, treatment received, and outcomes.

\section{Statistical Analysis}

For statistical analysis purposes, we tabulated results of outcomes into two groups: those who improved clinically and those who did not improve. The results were analyzed using chi-square test and $t$-test. $p$-Value of $<0.05$ was considered to be significant.

\section{Results}

We reviewed the literature from 1904 onwards and found a total of 170 articles describing this entity ( - Supplementary Table S1, details of SEAC articles). Thus a total of cases of 575 SEACs have been reported in world literature. Average age of presentation was 30 years (range: 5 months to 77 years), 274 were males, 266 were females, and data for 35 cases were not available (male:female ratio of 1.03:1). SEACs were located most commonly in the thoracic region, 42.3\% (218/515), followed by thoracolumbar, 27.9\% (144/515), lumbosacral, 10.3\% (53/515), lumbar 8.5\% (44/515), sacral, 5.8\% (30/515), cervical region, $2.9 \%$ (15/515), and cervicothoracic, $2.13 \%$ (11/515). Five cases had multiple locations of SEAC and data were not available for the remaining 55 cases.

The length of cyst was described in 444 patients. It was three or more vertebral levels in $85.81 \%(381 / 444)$ cases and $14.18 \%$ (63/444) had less than three vertebral level involvement. Overall, the average length of vertebral level involvement was 4.81 (standard deviation: 3.32).

In 314 cases, the data regarding type of clinical symptoms were available, in which 184 had motor symptoms (58.59\%), 159 had sensory involvement (50.63\%), and 46 cases had bowel/bladder symptoms (14.64\%). Details regarding duration of symptoms were described for 343/575 cases. The mean duration of symptoms was 28.99 months (range: 1-300 months; standard deviation: 41.61). More than half (204/343; 59.47\%) had symptom duration of more than 2 years. This suggests the long-standing course of this illness. Dural defect was described in 270 cases (46.95\%; - Table 1).

Outcome details were available for 410 patients. A good outcome with improvement in neurological status was found 
Table 1 Biodemographic and clinical profile of patients with SEAC $(N=575)$

\begin{tabular}{|c|c|}
\hline Variables & Frequency (\%) \\
\hline Age $(y)$ & $\begin{array}{l}\text { Mean: } 30 \\
\text { [range: } 0.5-77 \text { ] }\end{array}$ \\
\hline \multicolumn{2}{|l|}{ Gender } \\
\hline Male & $274(47.7)$ \\
\hline Female & $266(46.3)$ \\
\hline \multicolumn{2}{|l|}{ Presentation of cyst } \\
\hline Pure extradural & $566(98.5)$ \\
\hline Extradural with extraspinal extension & $04(0.7)$ \\
\hline Extradural with intradural component & $03(0.5)$ \\
\hline Interdural & $02(0.3)$ \\
\hline \multicolumn{2}{|l|}{ Dural defect } \\
\hline Present & $270(47.0)$ \\
\hline Absent/not described & $305(53.0)$ \\
\hline \multicolumn{2}{|l|}{ Location $(n=515)$} \\
\hline Thoracic & $218(42.3)$ \\
\hline Thoracolumbar & $144(27.9)$ \\
\hline Lumbosacral & $53(10.3$ \\
\hline Lumbar & $44(8.5)$ \\
\hline Sacral & $30(5.8)$ \\
\hline Cervical & $15(2.9)$ \\
\hline Cervicothoracic & $11(2.13)$ \\
\hline Multiple & $5(1.0)$ \\
\hline \multicolumn{2}{|l|}{ Length of cyst $(n=444)$} \\
\hline One vertebral level & $05(1.1)$ \\
\hline Two vertebral level & $58(13.1)$ \\
\hline Three vertebral level & 177 (39.9) \\
\hline Four vertebral level & $111(25.0)$ \\
\hline Five vertebral level & $29(6.5)$ \\
\hline$\geq 6$ vertebral level & $64(14.4)$ \\
\hline \multicolumn{2}{|l|}{ Clinical presentation $(n=314)$} \\
\hline Motor symptoms & $184(59.6)$ \\
\hline Sensory symptoms & $159(50.6)$ \\
\hline Bladder/bowel symptoms & $46(14.6)$ \\
\hline \multicolumn{2}{|l|}{ Symptom duration in years $(n=343)^{a}$} \\
\hline$<2$ & $139(40.5)$ \\
\hline$>2$ & $204(59.5)$ \\
\hline
\end{tabular}

Abbreviation: SEAC, spinal epidural arachnoid cyst.

aMean duration in month: 29.0 [range: 1-300].

in $79.26 \%$ patients ( 325 out of 410 cases), static neurological status despite intervention was seen in $18.53 \%$ (76 out of 410 ) cases, and worsening was seen in $2.19 \%$ (9 out of 410 ) cases. For the analysis of outcome, we divided patients into two categories: those who improved after intervention $(n=325)$ and those who did not improve $(n=85)$.
The second group included those patients who had static course of their illness despite intervention $(n=76)$ and those deteriorated clinically ( $n=9$ ).

On analyzing the factors affecting the surgical outcome, we found that there was significant improvement in the case of patients who underwent complete resection of SEAC (85.27\%) as compared with those who underwent partial resection or other conservative approaches (64.70\%) $(p=0.000037)$. The patients who improved had a shorter duration of symptoms (21.65 months) as compared with those who did not (53.89 months) $(p=0.000179)$. Those patients who were symptomatic in form of motor or sensory symptoms improved after surgery. Patients with bladder and bowel involvement also showed improvement but this could not reach a statistically significant value $(p=0.59)$. Age, sex, length of lesion, and presence of dural defect did not have a bearing on the surgical outcome (-Table 2).

Our experience: We had operated three cases of symptomatic SEAC, which have been included in this literature review. The average age was 18.7 years; two were females. Two cases were located in the thoracic region, while the remaining one was thoracolumbar. All presented with features of compressive myelopathy, average duration being 4.5 months. All of them had complete cyst excision with closure of the dural defect. They all improved in the postoperative period and up to 17 months of follow-up did not show any recurrence.

\section{Discussion}

SEACs have an incidence of approximately $1 \%$ of all the spinal lesions. ${ }^{6}$ Nonne in 1898 first found a case of SEAC at an autopsy. However, the first case of SEAC was operated by Schmidt in 1904 in a 16-year-old male. ${ }^{7}$ Cloward in 1968 reviewed literature of SEAC from 1904 to 1968 and reported 92 cases till that period, including two cases of his own. ${ }^{7}$ We could find 575 cases on systematic review of English literature. They were found equally affecting either sex and the average age of patients was found to be 30 years with the youngest reported case having the age of 5 months. We also encountered three cases of SEAC, two were females and one was male, with an average age of 18.7 years, youngest being a 10 -year-old male. Thus, SEAC is a disease of the younger age group.

It was found that thoracic and thoracolumbar regions are the most common locations of SEAC. Few case reports describe septated arachnoid cysts as described in the series by Cloward. ${ }^{7}$ Multiple SEACs are rare. ${ }^{8}$ Two of our cases were localized in the thoracic region, while the third one was in the thoracolumbar region. Among reviewed cases, the cyst was located posterior to the thecal sac in all, except in 12 cases $(0.06 \%)$ where it was found anterior. Over $85 \%$ of cases had a length more than three vertebral levels with an average length of 4.81 vertebral levels among all cases. All three of our cases had a longitudinal extent greater than three vertebral levels.

Pathogenesis of SEAC in not yet completely understood. Several theories have been described regarding the 
Table 2 Association of biodemographic and clinical parameters with outcome of disease

\begin{tabular}{|c|c|c|c|}
\hline Variables & $\begin{array}{l}\text { Improved } \\
(n=325)\end{array}$ & $\begin{array}{l}\text { Not improved } \\
(n=85)\end{array}$ & $p$-Value \\
\hline Age (mean \pm SD) & $29.1 \pm 15.4$ & $30.4 \pm 22.1$ & 0.35 \\
\hline \multicolumn{4}{|l|}{ Gender } \\
\hline Male & $138(86.3)$ & $22(13.8)$ & \multirow[t]{2}{*}{0.89} \\
\hline Female & $144(86.7)$ & $22(13.3)$ & \\
\hline Length/size of lesion in vertebral segments (mean \pm SD) & $5.17(5.8)$ & $5.21(3.1)$ & 0.486 \\
\hline Duration of preoperative symptom duration in months (mean \pm SD) & $21.64(23.91)$ & $53.89(76.57)$ & 0.000179 \\
\hline \multicolumn{4}{|l|}{ Predominant symptoms } \\
\hline Motor weakness & $184(84.8)$ & $33(15.2)$ & 0.0034 \\
\hline Sensory symptoms & $159(88.8)$ & $20(11.2)$ & 0.000026 \\
\hline Bladder/bowel involvement & $46(76.6)$ & $14(23.3)$ & 0.59 \\
\hline \multicolumn{4}{|l|}{ Dural defect } \\
\hline Present $^{\mathrm{a}}$ & $170(80.56)$ & $41(19.4)$ & \multirow[t]{2}{*}{0.503} \\
\hline Absent/not described $^{\mathrm{b}}$ & $155(77.9)$ & $44(22.1)$ & \\
\hline \multicolumn{4}{|l|}{ Type of treatment $(n=343)$} \\
\hline Complete excision & $220(85.3)$ & $38(14.7)$ & \multirow[t]{2}{*}{0.000037} \\
\hline Partial excision and conservative & $55(64.7)$ & $30(35.3)$ & \\
\hline
\end{tabular}

Abbreviation: SD, standard deviation.

${ }^{\mathrm{a}}$ Out of 270 cases who had presence of dural defect described, outcome data were available for 211 cases only.

${ }^{b}$ Out of 305 cases who either did not describe presence of dural defect or it could not be found despite search, outcome data were available for 199 cases.

formation of cyst. Extradural arachnoid cysts develop from arachnoidal herniation through a defect in the spinal dura at or near a nerve root, or in the midline. ${ }^{9}$ This communication can be congenital, idiopathic, or acquired. Elsberg et al first described the cyst to be a congenital diverticulum of the dura, or protrusion of arachnoid through the defect or weak place in the dura. ${ }^{7}$ Ogura et $\mathrm{al}^{10}$ investigated idiopathic SEAC and clarified that there are two types of idiopathic SEAC, sporadic (isolated) and syndromic (familial). Mutations in HOXD4 and FOXC2 genes have been identified in sporadic and syndromic cases respectively. Familial cases are associated with lymphedema-distichiasis syndrome, whose causal gene is FOXC2. Multiple SEACs may be associated with FOX2 mutations.

Whether congenital or acquired (trauma, arachnoiditis, or iatrogenic events), a small dural tear allows cerebrospinal (CSF) pressure to initiate herniation of the arachnoid membrane through the defect. This defect is usually found near the dural nerve root sleeve. A possible explanation for such tears is the stretching force between the movable thecal sac and the relatively fixed roots. The chances of a dural tear increase if the patients have underlying structural problems (e.g., connective tissue disorders) or thecal sac movements due to trauma or CSF leakage. ${ }^{1}$ Cho et al have described the neural-dural transition at thoracic and lumbar nerve roots in the human embryonal studies. ${ }^{11}$ They found a tortuous transition zone in the dorsal nerve root region as compared with the ventral nerve root. This could be a site of weakness, which ruptures with trivial trauma and causes herniation of arachnoid membrane leading to formation of epidural cysts. History of trauma was present in two of our cases, which could have led to epidural cyst formation from the weak dural nerve root sleeve. A defect in the dura seems to be plausible explanation for the cyst formation as was found in all our cases. We found dural defect in these cases near the dural root sleeve area.

As discussed earlier, the average age of presentation of all analyzed cases is 30 years, which may indicate possibilities of combination of factors, such as genetic predisposition with minor trauma in young physically active individuals.

Various mechanisms have been postulated to explain the expansion of the cyst. Active (noncommunicating arachnoid cyst) and passive (ball-valve) fluid-transport mechanisms have been hypothesized to explain enlargement of extradural meningeal cysts. According to the first theory, an arachnoid cyst may enlarge even when it does not communicate with the subarachnoid space (noncommunicating arachnoid cyst) because of fluid production by the cells forming its wall. ${ }^{12}$ The second theory (the ball-valve hypothesis) postulates the existence of an anatomical communication functioning as a one-way valve between the subarachnoid space and the cyst, which allows the CSF to enter the cystic cavity (communicating cyst). ${ }^{13}$

Most of the patients present with features of longstanding compressive myelopathy. Some also had finding of local or radiculopathic pain especially in the early stages. Our analysis revealed that 59\% patients had motor weakness, $50 \%$ patients had sensory involvement, and around 14\% 
patients had bowel and bladder involvement. It has been suggested that pressure on the adjacent sensitive tissue, such as the periosteum and the joint capsule, may cause local pain. The radicular pain may be due to distortion, compression, or stretching of the root by the cyst. ${ }^{14}$ Nerve root prolapse into the cyst can also lead to radicular symptoms. ${ }^{15}$ They may also present with sensory abnormalities, most commonly the dorsal column involvement. Bowel and bladder involvement is quite late in these patients. The intermittent exacerbations of pain and neurological symptoms are explained by postural changes and Valsalva maneuvers. ${ }^{14}$ The overall duration of symptoms in reviewed cases is around 29 months, which suggest the long-standing nature of the illness. Some unusual presentations have been described. Long-standing cases can present with bony spinal deformity. ${ }^{4}$ Sacral arachnoid cyst causing holocord syrinx due to secondary tethering effect has been described. There was resolution of syrinx after excision of the cyst. ${ }^{16}$ Arachnoid cyst in the cervical region may also masquerade as obstetric brachial palsy in case of children. ${ }^{17}$ Association of SEAC with split cord malformation has also been reported. ${ }^{18}$ Retroperitoneal extension of the cyst can also present with abdominal symptoms. ${ }^{19}$ Bond et al described three patients in whom SEAC was incidentally detected on MRI. ${ }^{12}$ All the three patients reported by us had features of compressive myelopathy with a mean duration of symptoms of 4.5 months.

One can have indirect nonspecific changes on plain X-ray such as slender pedicles, bony erosions, foraminal enlargements, and widening of the spinal canal. ${ }^{20} \mathrm{CT}$ myelography or water-soluble contrast myelography may be helpful to find the communicating site between the cyst and the subarachnoid space. MRI is the diagnostic procedure of choice, since it has shown to have high sensitivity as well as specificity and is noninvasive. A SEAC has a low signal intensity on a T1-weighted image (WI) and high signal intensity on a T2-WI, similar to CSF fluid. It delineates well the relation of cyst with the spinal cord and nerve roots. ${ }^{21}$ Contrast imaging is used to differentiate between cystic tumors, synovial cysts, and other cystic lesions. Presence of dural defect was described in 270 cases $(46.95 \%)$ in the literature, reflecting a need to innovate methods for appropriate preoperative localization of the defect.

Kinematic MRI is a recently developed technique that visualizes fluid and tissue movement, demonstrates the pathomechanism of turbulent flow voiding, and detects dural defects. $^{22}$ Non-contrast-enhanced time-spatial labeling inversion pulse MRI sequences are used to successfully visualize CSF fluid flow (nonturbulent flow) through communicating holes of an SEAC to localize the dural defect. ${ }^{23}$ It has been useful in facilitating a minimal invasive approach for such cases. ${ }^{24}$ Ultrasound has also been used intraoperatively when other imaging modalities have failed to identify the communication site. ${ }^{25}$

Literature analysis revealed that 35 cases were managed conservatively for the SEAC while the remaining 540 underwent intervention. Various surgical options described in the literature include simple cyst aspiration ${ }^{26}(n=8)$, marsupialization $^{27}(n=12)$, partial $\operatorname{excision}^{2,3} \quad(n=10)$, closure of the defect without cyst excision ${ }^{3}(n=27)$, and complete microsurgical excision $(n=407)$. Dural defect repair was described in 270 of these cases. Complete microsurgical excision of the cyst and repair of the dural defect were done in all of our cases with good outcome and no complications.

It is prudent to excise cyst along with closure of defect (if any), wherever possible. However, in case of extensive cysts or anteriorly placed cysts, conservative measures like fenestration may be the appropriate choice. Cystoperitoneal shunting has also been used in refractory cases. ${ }^{28}$ Epidural blood patch placement to occlude the dural defect has also been tried in anterior extradural arachnoid cyst leading to stable disease course. $^{29}$ Expansive duraplasty has been reported in case of thick, fibrous cyst which was difficult to dissect of the dura. The dural wall was reconstructed using the tough cyst wall layer in an expansile manner leading to resolution of symptoms. ${ }^{30}$ Multiple SEACs, long-segment SEAC, can be managed by limited laminectomy and closure of the defect, thus preventing spinal instability. ${ }^{31}$ A retrospective study was done by Kunz et al comparing operative versus conservative management in lumbar SEAC. They concluded that the results of conservative treatment were nearly the same as those of operative treatment and patients with a short pain history and a clear neurological deficit profited most from surgery. Those patients with slight and not clearly related uncharacteristic symptoms should be excluded from surgery. ${ }^{32}$ Thus, incidentally discovered SEAC causing no symptoms can be observed.

No correlation exists between the size of a cyst alone and the need for treatment. They can be followed up with yearly imaging to detect new abnormality and determine whether the cyst is truly benign. ${ }^{33}$ Surgery is recommended for large cyst exerting mass effect and with associated symptoms. ${ }^{14}$ On systemic review of the literature, we found that a good clinical outcome was present in symptomatic patients, who had shorter symptom duration and underwent complete surgical excision of the SEAC ( - Table 2, outcome analysis).

Lee et $\mathrm{al}^{3}$ have described that the recurrence of the SEAC was related to the repair of the dural defect and not to the completeness of SEAC excision. The incidence rate of SEAC recurrence was $2 \%$ for the patients with repaired dural defects as compared with $10 \%$ for the patients with completely excised cysts without repair of the dural defect. There was no cyst recurrence in any of our cases at an average follow-up of 17 months. Thus, a meticulous identification and closure of the dural defect in case of SEAC may help in preventing recurrence. As described earlier, intraoperative ultrasonography can be a valuable adjunct in cases where defect localization is difficult.

In the study by Morizane et al, ${ }^{13}$ the three cases which had poor outcome following surgery, they were unable to find out any significant difference in age, sex, duration of symptoms before surgery, location and shape of SEACs, 
operative method, and follow-up. Kendall et al ${ }^{34}$ also could not find any preoperative distinction between the cases that had neurological improvement and those which did not. However, the mean age of the former (35 years) was less than the latter (44 years), the duration of paresis was shorter in those who improved (mean: 2 years) than in those who did not (mean: 4.8 years). Analysis of all cases where outcome data were available reveals that patients with improvement had a significantly short duration of symptoms than those who did not ( 21 vs. 53 months). Thus, outcome may be related to the duration of symptom, a longer duration having a poor outcome due to long-standing changes in the spinal cord. In cases of myelomalacia secondary to cyst pressure, postoperative results are quite poor. ${ }^{8}$ All of our cases had a short duration of symptoms and recovered well after surgery.

\section{Conclusion}

SEAC should be considered in differential of cystic spinal lesions presenting as compressive myelopathy in the younger age group. MRI being the investigation of choice, radiological localization of the dural defect preoperatively helps in management. Improvement in outcome is significantly related with a shorter duration of symptom, clinically symptomatic patients, and those patients who had complete excision of the cyst. Thus, we advocate an early, complete microsurgical excision of the lesion along with meticulous closure of the dural defect in symptomatic patients for a good outcome and prevention of recurrence.

\section{Funding \\ None.}

Conflict of Interest

None declared.

\section{References}

1 Lee SW, Foo A, Tan CL, et al. Spinal extradural cyst: case report and review of literature. World Neurosurg 2018;116:343-346

2 Woo JB, Son DW, Kang KT, et al. Spinal extradural arachnoid cyst. Korean J Neurotrauma 2016;12(02):185-190

3 Lee C-H, Hyun S-J, Kim K-J, Jahng T-A, Kim H-J. What is a reasonable surgical procedure for spinal extradural arachnoid cysts: is cyst removal mandatory? Eight consecutive cases and a review of the literature. Acta Neurochir (Wien) 2012;154(07): 1219-1227

4 Liu JK, Cole CD, Kan P, Schmidt MH. Spinal extradural arachnoid cysts: clinical, radiological, and surgical features. Neurosurg Focus 2007;22(02):E6

5 Funao H, Nakamura M, Hosogane N, et al. Surgical treatment of spinal extradural arachnoid cysts in the thoracolumbar spine. Neurosurgery 2012;71(02):278-284, discussion 284

6 Netra R, Min L, Shao Hui M, Wang JC, Bin Y, Ming Z. Spinal extradural meningeal cysts: an MRI evaluation of a case series and literature review. J Spinal Disord Tech 2011;24(02): 132-136

7 Cloward RB. Congenital spinal extradural cysts: case report with review of literature. Ann Surg 1968;168(05):851-864
8 Ergun T, Lakadamyali H. Multiple extradural spinal arachnoid cysts causing diffuse myelomalacia of the spinal cord. Neurologist 2009;15(06):347-350

9 Rengachary SS, O'Boynick P, Karlin CA, Batnitzky S, Price H. Intrasacral extradural communicating arachnoid cyst: cases report. Neurosurgery 1981;8(02):236-240

10 Ogura Y, Fujibayashi S, Iida A, et al. A novel FOXC2 mutation in spinal extradural arachnoid cyst. Hum Genome Var 2015; 2:15032

11 Cho KH, Jin ZW, Abe H, Shibata S, Murakami G, Rodríguez-Vázquez JF. Neural-dural transition at the thoracic and lumbar spinal nerve roots: a histological study of human late-stage fetuses. BioMed Res Int 2016;2016:8163519

12 Bond AE, Zada G, Bowen I, McComb JG, Krieger MD. Spinal arachnoid cysts in the pediatric population: report of 31 cases and a review of the literature. J Neurosurg Pediatr 2012;9(04): 432-441

13 Morizane K, Fujibayashi S, Otsuki B, et al. Clinical and radiological features of spinal extradural arachnoid cysts: valve-like mechanism involving the nerve root fiber as a possible cause of cyst expansion. J Orthop Sci 2018;23(03):464-469

14 Marbacher S, Barth A, Arnold M, Seiler RW. Multiple spinal extradural meningeal cysts presenting as acute paraplegia. Case report and review of the literature. J Neurosurg Spine 2007;6(05): 465-472

15 Sangala JR, Uribe JS, Park P, Martinez C, Vale FL. Nerve root prolapse into a spinal arachnoid cyst-an unusual cause of radiculopathy. Clin Neurol Neurosurg 2009;111(05):460-464

16 Thakar S, Kiran NAS, Hegde AS. A sacral arachnoid cyst causing holocord syringomyelia. J Neurosurg Pediatr 2011;8(03): 299-302

17 Muthukumar N, Santhanakrishnan AG, Sivakumar K. Arachnoid cyst masquerading as obstetric brachial plexus palsy. J Neurosurg Pediatr 2012;10(01):62-63

18 Habibi Z, Hanaei S, Nejat F. Sacral extradural arachnoid cyst in association with split cord malformation. Spine J 2016;16(09): 1109-1115

19 Park S-H, Kuh S-U, Lim BJ. Retroperitoneal spinal extradural arachnoid cyst combined with congenital hemivertebrae. J Korean Neurosurg Soc 2012;52(03):257-260

20 Rimmelin A, Clouet PL, Salatino S, et al. Imaging of thoracic and lumbar spinal extradural arachnoid cysts: report of two cases. Neuroradiology 1997;39(03):203-206

21 Boisserie-Lacroix M, Bouin H, Joullie M, et al. The value of MRI in the study of spinal extradural arachnoid cysts. Comput Med Imaging Graph 1990;14(03):221-223

22 Doita M, Nishida K, Miura J, Takada T, Kurosaka M, Fujii M. Kinematic magnetic resonance imaging of a thoracic spinal extradural arachnoid cyst: an alternative suggestion for exacerbation of symptoms during straining. Spine 2003;28(12): E229-E233

23 Ishibe T, Senzoku F, Ikeda N, Kamba Y, Mikawa Y. Detection of the communicating hole(s) of spinal extradural arachnoid cysts using time-spatial labeling inversion pulse magnetic resonance imaging. Spine 2014;39(23):E1394-E1397

24 Neo M, Koyama T, Sakamoto T, Fujibayashi S, Nakamura T. Detection of a dural defect by cinematic magnetic resonance imaging and its selective closure as a treatment for a spinal extradural arachnoid cyst. Spine 2004;29(19):E426-E430

25 Kanetaka M, Sugita S, Chikuda H, et al. Use of Doppler ultrasonography to detect an elusive communication of a spinal extradural arachnoid cyst. J Clin Neurosci 2011;18(06):863-864

26 Bellavia R, King JT Jr, Naheedy MH, Lewin JS. Percutaneous aspiration of an intradural/extradural thoracic arachnoid cyst: use of MR imaging guidance. J Vasc Interv Radiol 2000;11(03): 369-372 
27 Uemura K, Yoshizawa T, Matsumura A, Asakawa H, Nakamagoe K, Nose T. Spinal extradural meningeal cyst. Case report. J Neurosurg 1996;85(02):354-356

28 James HE, Postlethwait R. Spinal peritoneal shunts for conditions other than hydrocephalus and pseudotumor cerebri: a clinical report. Pediatr Neurosurg 2007;43(06):456-460

29 Lee TP, Twydell P, Li Y. Anterior spinal extradural cyst mimicking hirayama disease and amyotrophic lateral sclerosis. RRNMF Neuromuscul J 2020;1(1)

30 Kikuta K, Hojo M, Gomi M, Hashimoto N, Nozaki K. Expansive duraplasty for the treatment of spinal extradural arachnoid cysts: case report. J Neurosurg Spine 2006;4(03):251-255
31 Tsuchimochi K, Morioka T, Murakami N, Yamashita F, Kawamura N. Huge multiple spinal extradural meningeal cysts in infancy. Childs Nerv Syst 2019;35(03):535-540

32 Kunz U, Mauer UM, Waldbaur H. Lumbosacral extradural arachnoid cysts: diagnostic and indication for surgery. Eur Spine J 1999;8(03):218-222

33 Hughes G, Ugokwe K, Benzel EC. A review of spinal arachnoid cysts. Cleve Clin J Med 2008;75(04):311-315

34 Kendall BE, Valentine AR, Keis B. Spinal arachnoid cysts: clinical and radiological correlation with prognosis. Neuroradiology 1982;22(05):225-234 